\title{
Regular, moderate intensity maternal exercise reduces birth weight but increases the risk of later childhood adiposity
}

\author{
Valentina Chiavaroli", Sarah Hopkins, Janene Biggs, José Derraik, Raquel Olmedo Rodrigues, Wayne Cutfield, \\ Paul Hofman
}

From 8th APPES Biennial Scientific Meeting

Darwin, Australia. 29 October - 1 November 2014

\section{Aims}

We have previously randomised primiparous mothers to either an exercise regime or normal activity between 20 and 36 weeks gestation. In this study we aimed to assess the long-term effects of exercise during pregnancy on growth parameters and body composition in the offspring over their first 6-8 years of life.

\section{Methods}

Of the initial 84 women and their offspring who participated in the RCT, follow-up data were available on 46 mothers (26 exercisers, 20 controls) and 46 children. At each follow-up visit (6 months, 1 year, 2 years, 4 years, 6-8 years) clinical assessment included measurement of mothers' and children's heights, weights, BMI, and waist circumference, as well as blood pressure. Body composition was assessed in both mothers and children by whole-body dual-energy X-ray absorptiometry (DXA) scans at 4-year and 7-year follow-up visits.

\section{Results}

There were no differences in anthropometry between exercise and control children in the first 2 years of life. In addition, at age 4 years there were no differences in height, BMI, percentage body fat, or waist circumference between the two groups. At a mean age of $\sim 7.5$ years, exercise and control children showed similar weight, height, BMI, and waist circumference, but the exercise group had more body fat ( 17.5 vs $16.0 \%, \mathrm{P}=0.02)$ than controls. Over the course of follow-up there were no observed differences in anthropometry between exercise and control mothers.

Liggins Institute, University of Auckland, Auckland, New Zealand

\section{Conclusion}

While no long-term benefits of maternal exercise in the first pregnancy were noted in mothers, children exposed to maternal exercise during intrauterine life appear prone to greater fat mass accumulation in mid-childhood. Larger studies are required to confirm this important observation as exercise in pregnancy is widely recommended by obstetricians.

Published: 28 April 2015

\section{doi:10.1186/1687-9856-2015-S1-043}

Cite this article as: Chiavaroli et al:: Regular, moderate intensity maternal exercise reduces birth weight but increases the risk of later childhood adiposity. International Journal of Pediatric Endocrinology 2015 2015(Suppl 1):043

\section{Submit your next manuscript to BioMed Central and take full advantage of: \\ - Convenient online submission \\ - Thorough peer review \\ - No space constraints or color figure charges \\ - Immediate publication on acceptance \\ - Inclusion in PubMed, CAS, Scopus and Google Scholar \\ - Research which is freely available for redistribution

